Калийкан Бирлик Калийканулы, Магистрант Восточно-Казахстанский Государственный Технический Университет имени Д.Серикбаева г. Усть-Каменогорск, Казахстан. E-mail: master_birlik06833005@mail.ru ORCID ID 0000-0001-7098-1017

\title{
ВЕРОЯТНОСТНЫЙ РАСЧЕТ И ОЦЕНКА НАДЕЖНОСТИ СТЕРЖНЕВЫХ КОНСТРУКЦИЙ
}

\author{
Birlik Kaliikanuly Kaliikan, Magister \\ D.Serikbayev East Kazakhstan State Technical University \\ City Ust'-Kamenogorsk, Kazakhstan \\ E-mail: master_birlik06833005@mail.ru
}

ORCID ID 0000-0001-7098-1017

\section{PROBABILISTIC CALCULATION AND EVALUATION OF RELIABILITY OF ROD DESIGNS}

Annotation: This article describes the probabilistic calculations of rod structures for solving problems of structural mechanics and resistance of materials. The analysis was carried out on the method of deterministic calculation of the rod structure, taking into account the stochastic nature of the factors. Describes the analysis of which probabilistic calculations and on which constructions the most extensive problems are now.

Keywords: the method of deterministic calculation, reinforced concrete structures with mixed reinforcement.

Аннотация: Данная статья описывает вероятностные расчеты стержневых конструции решений задач строительной механики и сопротивления материалов. Был проведен анализ на метод детерминированного расчета стержневой структуры с учетом стохастического характера факторов. Описывает анализ какие вероятностные расчеты и на какие конструкиии самые обширные проблемы сейчас.

Ключевые слова: метод детерминированного расчета, железобетонные конструкции со смешанным армированием.

Дальнейшее совершенствование строительных конструкций и повышение их надежности невозможно без дальнейшего совершенствования методов их расчета. В настоящее время большое внимание уделяется расчету строительных конструкций с учетом стохастической природы различных факторов. В строительной промышленности геометрические и прочностные характеристики, а также нагрузки являются случайными. При этом проектирование строительных конструкций должно осуществляться с учетом стохастического характера.

Для этого при проектировании строительных конструкций учитывается стохастический характер различных факторов необходим для того, чтобы иметь удобные и простые в практике вероятностные методы расчета, так как они позволят оценить надежность строительных конструкций. В настоящее время развитие информационных технологий и компьютерных технологий позволяет изменить подход к вероятностным расчетам строительных конструкций. Такое использование численного моделирования 
позволяет избежать каких-либо ограничений на характер исходной статистики информация расчет коэффициентов, размерность задачи.

Комплексные задачи по расчету основных строительных конструкций с учетом случайные характеристики рассматривались в работах Н. А. Булычева, В. Д. Рейзера и А. прочностных характеристик и стохастических свойств внешних нагрузок и воздействий, поэтому этот вопрос остается несколько понятным. В большинстве случаев эти расчеты выполняются для отдельных конструктивных элементов, но не для реальных конструктивных систем.

Для этого необходимо решить следующие задачи: разработать метод детерминированного расчета стержневой структуры ферменного или балочного типа; разработать метод расчета вероятности стержневой структуры с учетом стохастического характера факторов, определяющих сопротивление. Цель и расчетное прогнозирование и регулирование эксплуатационных затрат возможно только путем оценки надежности конструкций на этапах их изготовления, строительства и эксплуатации. Основные методы получения таких оценок разработаны в теории надежности строительных конструкций.

В настоящее время уровень надежности современных нормативных документов четко неясен и отражен в системе частных коэффициентов надежности - по нагрузке, по материалу, по назначению здания или сооружения и по условиям работы строительных конструкций. В результате однотипные конструкции, разработанные в соответствии с регламентом, имеют разный уровень надежности, что видно и влияет на производительность конструкции - стоимость материалов, выработка энергии, себестоимость и другие факторы.

Эффективность и надежность-необходимое качество возводимых, проектируемых и эксплуатируемых сооружений, зданий и сооружений. Обеспечение этих качеств особенно важно при поиске новых конструктивных решений.

Однако переход к рыночной экономике привел к разрушению существующих взаимоотношений между исполнителями строительного процесса. В этой ситуации становится актуальным поиск на сокращение в первом сметной стоимости строительства на основе развития ресурсосберегающих технологий по производству строительных материалов и изделий, эффективных материалов и конструкций, а во-вторых-масштабы деятельности, включая создание четкой системы профилактических ремонтов, накопление информации о структурных повреждений и другие.

Среди наиболее экономичными и перспективными являются железобетонные конструкции, содержащие натягиваемую и ненапряженной арматуры, т. е. со смешанным армированием. Так они в розницу преимущества преднапряженных элементов и безударные. Эффективность таких конструкций в основном определяется повышением их надежности за счет ослабления влияния случайных факторов, которые присущи способам предварительного напряжения и характеристикам высокопрочного армирования. В условиях, которые обеспечивают работу ненапрягаемой арматуры расчетное сопротивление или близкое к нему, смешанное армирование может обеспечить снижение расхода стали. Однако в этом случае количество предварительно напряженной высокопрочной арматуры и арматуры в целом уменьшается, так как обычная арматура может располагаться только в тех местах, где это необходимо для расчета. Уменьшение количества устройств предварительного натяжения (анкеров, натяжителей, болтов, хомутов и др.) и технологические затраты на электроэнергию дополняют экономическую целесообразность использования конструкций со смешанной арматурой. 
Анализ на надежности нецентрального сжатого стального стержня в предположении различных деформационных моделей: упругопластической, упругой, основанной на Формуле Мерчанта. Полученные решения сравниваются с результатами статистической линеаризации. В это время строится алгоритм решения задачи, когда заданные размеры поперечного сечения здесь, $\mathrm{f}_{\mathrm{c}}$ одноосная удельная работа разрыва, $\mathrm{f}_{\mathrm{t}}$ одноосная прочность стержня определяют его интенсивность отказов и наоборот, когда заданная интенсивность отказов определяет размер поперечного сечения, т. е. решается обратная задача. Кроме того, проинвестирована зависимость вероятности безотказной работы от гибкости стержня при нагружении продольными и переносными случайными нагрузками и при произвольной точке текучести. В этом случае задача решается в упругопластической постановке. В связи с рассмотрением задачи комбинирования нагрузок предложен алгоритм определения комбинации, зависящей от доли передаточной нагрузки в общем воздействии. Рассмотрим расчет плотного каркаса стеллажа. Конструктивная схема сжатого стержня сводится к центру при случайных эксцентриситетах продольной силы.

Вывод. Поэтому разработка таких методов вероятностного расчета проектирование активной зоны и оценка вероятности безотказной работы такого конструкции самая обширная проблема. Железобетонные конструкции со смешанной арматурой, в отличие от полностью напряженных и ненапряженных, обладают большей гибкостью, что особенно важно при строительстве в сейсмических районах. Снижение прочности на сжатие в конструкциях со смешанным армированием значительно уменьшает потери предварительного напряжения от быстрой и длительной ползучести бетона. От этого возможно уменьшить ранг бетона и свою прочность перехода, для того чтобы облегчить работу подкреплений. Так как оценка надежности железобетонных конструкций со смешанной арматурой практически не проводится до сих пор. Поэтому очевидно, что новые свойства таких конструкций требуют анализа применяемых методов расчета и оценки их надежности с позиций теории надежности.

\section{СПИСОК ЛИТЕРАТУРЫ}

1. https://ru.wikipedia.org/wiki/Вероятностный расчет строительных конструкции

2. Расчет стержневых конструкций с учетом пластических деформаций материала: Волошановская Ю. Э., Тихонова О. Н. Издатель: Директ-Медиа, 2014

3. Вероятностные методы и теория надёжности в расчётах строительных конструкций В.Г. Себешев 2009-2011г

4. Rakenteiden Mekaniikka (Journal of Structural Mechanics) Vol. 47. No 2. 2014. pp. 50 - 66

5. https://www.comsol.ru/structural-mechanics-module

6. Аугуети, Г. Вероятностные методы в строительном проектировании / Г. Аугуети, А. Баратти, Ф. Кашиати ; пер. с англ. - М. : Стройиздат, 1988. - 584 с.

7. Болотин, В.В. Методы теории вероятностей и теории надёжности в расчётах зданий и Стройиздат, 1982.

8. Вероятностные методы строительной механики и теория надежности строительных конструкций: учебное пособие : 2-х частях, Ч. І Издатель: Волгоградский государственный архитектурно-строительный университет, 2015

9. Журнал инженерная механика (C обсе / январь 2010 / 5

10. Справочник проектировщика. - М.: Литературы по строительству, 2018. - 272 с 